\title{
Population structure in Neotropical plants: integrating pollination biology, topography and climatic niches
}

\author{
Agnes Dellinger ${ }^{1}$, Ovidiu Paun ${ }^{2}$, Juliane Baar ${ }^{2}$, Eva Temsch ${ }^{2}$, Diana \\ Fernández-Fernández ${ }^{3}$, and Jürg Schönenberger ${ }^{2}$ \\ ${ }^{1}$ University of Colorado Boulder \\ ${ }^{2}$ University of Vienna \\ ${ }^{3}$ Instituto Nacional de Biodiversidad
}

November 24, 2021

\begin{abstract}
Animal pollinators mediate gene flow among plant populations, but, in contrast to well-studied topographic and (Pleistocene) environmental isolating barriers, their impact on population genetic differentiation remains largely unexplored. Comparatively investigating how these multifarious factors drive microevolutionary histories is, however, crucial for better resolving macroevolutionary patterns of plant diversification. We here combined genomic analyses with landscape genetics and niche modelling across six related Neotropical plant species (424 individuals across 33 localities) differing in pollination strategy to test the hypothesis that highly mobile (vertebrate) pollinators more effectively link isolated localities than less mobile (bee) pollinators. We found consistently higher genetic differentiation (FST) among localities of bee- than vertebrate-pollinated species with increasing geographic distance, topographic barriers and historic climatic instability. High admixture among montane populations further suggested relative climatic stability of Neotropical montane forests during the Pleistocene. Overall, our results indicate that pollinators may differentially impact the potential for allopatric speciation, thereby critically influencing diversification histories at macroevolutionary scales.
\end{abstract}

Title: Population structure in Neotropical plants: integrating pollination biology, topography and climatic niches

Running title : Population structure in Neotropical plants

Agnes S. Dellinger ${ }^{1,2}$, Ovidiu Paun ${ }^{1}$, Juliane Baar ${ }^{1}$, Eva M. Temsch ${ }^{1}$, Diana Fernández-Fernández ${ }^{3}$, Jürg Schönenberger ${ }^{1}$

${ }^{1}$ Department of Botany and Biodiversity Research, University of Vienna, Austria

${ }^{2}$ Ecology and Evolutionary Biology, University of Colorado, Boulder, USA

${ }^{3}$ QCNE, Instituto Nacional de Biodiversidad, Quito, Ecaudor

Corresponding author : Agnes S. Dellinger, Ecology and Evolutionary Biology, University of Colorado, Boulder, 1800 Colorado Ave., 80309 Boulder, USA. agnes.dellinger@univie.ac.at, +1 720 7364378. Orcid: 00000003-1394-3414

\section{Abstract}

Animal pollinators mediate gene flow among plant populations, but, in contrast to well-studied topographic and (Pleistocene) environmental isolating barriers, their impact on population genetic differentiation remains 
largely unexplored. Comparatively investigating how these multifarious factors drive microevolutionary histories is, however, crucial for better resolving macroevolutionary patterns of plant diversification. We here combined genomic analyses with landscape genetics and niche modelling across six related Neotropical plant species (424 individuals across 33 localities) differing in pollination strategy to test the hypothesis that highly mobile (vertebrate) pollinators more effectively link isolated localities than less mobile (bee) pollinators. We found consistently higher genetic differentiation $\left(F_{S T}\right)$ among localities of bee- than vertebrate-pollinated species with increasing geographic distance, topographic barriers and historic climatic instability. High admixture among montane populations further suggested relative climatic stability of Neotropical montane forests during the Pleistocene. Overall, our results indicate that pollinators may differentially impact the potential for allopatric speciation, thereby critically influencing diversification histories at macroevolutionary scales.

Keywords : pollinator shifts, population differentiation, genetic diversity, Pleistocene climatic fluctuations, mountain biodiversity, tropical rain forests, Andes, Melastomataceae

\section{Introduction}

Seed plant populations may be linked through two key ecological processes: pollen and seed dispersal (Krauss et al. 2008, Ballesteros-Mejia et al. 2016, Gelmi-Candusso et al. 2017, Cortés et al. 2018). Pollen dispersal by animals in particular is considered as major driver of plant population structure, often more important than seed dispersal (Yu et al. 2010, Clavino-Cancela et al. 2012, Kartzinel et al. 2013, Skogen et al. 2019, Gamba \& Muchhala 2020, Nazareno et al. 2021). Animal pollinators differ markedly in their mobility, flower-visitation behaviour and rates of pollen transfer (Bawa 1992, Breed et al. 2015, Krauss et al. 2017, Dellinger et al. 2021). These differences may result in distinct within-population mating patterns and among-population differentiation (Wessinger 2021). Less mobile pollinators (i.e. small insects, territorial hummingbirds) may generate localized mating patterns between neighbouring individuals, increased inbreeding, and high population differentiation (Schoen \& Clegg 1984, Opedal et al. 2017, Schmidt-Lebuhn et al. 2019, Wessinger 2021). Highly mobile pollinators (i.e. flying vertebrates, large bees), in contrast, may promote outcrossing and gene flow over larger geographic distances (Hughes et al. 2007, Whelan et al. 2009, Ballesteros-Mejia et al. 2016, Gamba \& Muchhala 2020). Understanding the extent to which different animal pollinators drive genetic differentiation, ultimately affecting the potential for adaptive evolution and speciation, is essential for better resolving macroevolutionary processes of angiosperm diversification, but it is also of major relevance for choosing appropriate management strategies in human-altered landscapes and under current climate change (Hadley et al. 2012, Toon et al. 2014, Castilla et al. 2017). Surprisingly, however, the impact of different pollination strategies on population genetic parameters across related plant species (accounting for shared macroevolutionary background) has rarely been assessed (Barbará et al. 2007, Kramer et al. 2011).

Besides (pollinator-mediated) gene flow, a species' present-day population genetic structure may be influenced by climatic and demographic history, landscape features, and adaptation to distinct (and changing) abiotic environmental conditions (Helmstetter et al. 2020). Mountains in particular, with their highly heterogeneous, rugged terrain, create dispersal barriers and strong environmental gradients across small spatial and temporal scales, reinforcing population differentiation and, potentially, speciation (Kisel \& Barraclough 2010, SurgetGroba \& Kay 2013, Nevado et al. 2019). Accordingly, mountains across the world represent biodiversity hotspots with an exceptional number of recent (plant) radiations (Luebert \& Weigend 2014, Rahbek et al. 2018, Rangel et al. 2018). Several of these radiations coincide with phases of mountain uplift or Pleistocene glacial cycles (Cortés et al. 2018). Particularly the latter, inducing repeated periods of population isolation, range shifts and habitat recolonization, have left imprints in the current population genetic structure (Ornelas et al. 2013, Ortego et al. 2014, Escobar et al. 2020).

The tropical Andes represent one of the planet's biodiversity hotspots, encompassing lowland rainforests, montane cloud forests and Páramo grasslands (Gentry 1982). The effects of Pleistocene climatic fluctuations in these habitats are complex, with idiosyncratic responses documented among different groups of organisms and geographic regions (Ramírez-Barahona \& Eguiarte 2013, Vasconcellos et al. 2019). Some studies suggest that (cloud) forests were fragmented into small refugia at mid elevations during dry glacial periods, lea- 
ding to marked population structuring and a loss of genetic diversity ('dry-refugia hypothesis', Haffer 1969, Gutíerrez-Rodríguez et al. 2011). Other data indicate that Neotropical mountains remained moist, with a mere downward and consecutive upward migration of forest zones, resulting in diffuse population structuring and increased genetic diversity in continuously forested areas (e.g. Colombian Chocó; 'moist-forest hypothesis', Carnaval et al. 2009, Valencia et al. 2010, Ornelas et al. 2019, Hernández-Langford et al. 2020).

Clearly, with their vital role in mediating gene flow, pollinators differing in mobility have the capacity of exponentiating or offsetting isolating effects of geographic or climatic barriers. Importantly, pollinators are not independent of their abiotic environment either. The flower visitation activity of ectothermic insect pollinators in particular may be strongly reduced by adverse weather conditions prevalent in tropical mountains, while endothermic vertebrates are less affected by weather fluctuations (Cruden 1972, Dellinger et al. 2021). To date, however, we largely lack studies from related Neotropical plants differing in pollination strategy to evaluate the relative contributions of biotic interactions, the (current and historic) abiotic environment, and landscape features to structuring population genetic diversity. Connecting these factors, however, will ultimately improve our understanding of the microevolutionary dynamics underlying (Neo)tropical diversity.

Here, we explore the effects of multifarious factors (geographic distance, topography, habitat suitability, Pleistocene climatic instability, environment) on population genomic diversity and differentiation across six related Neotropical plant species (Merianieae, Melastomataceae) differing in pollination strategy (but not in seed dispersal, see Material and Methods). We aim to understand whether mating patterns are more localized (i.e. lower heterozygosity and nucleotide diversity, higher inbreeding, stronger within-population isolationby-distance) in localities of bee-pollinated species (two species) than of vertebrate-pollinated species (four species), and whether flying vertebrate pollinators consistently promote higher levels of gene flow across larger (geographical, environmental) distances than bees. We further expect stronger effects of variation in climatic conditions in bee- than in vertebrate-pollinated species given the strong link between abiotic conditions and the activity of ectothermic insect pollinators. For each species, we contrast two adjacent $(<$ $12 \mathrm{~km}$ ) localities against three to four more distant localities and directly address differences in distribution ranges and ecosystems colonized through niche modelling approaches.

\section{Detailed Methods description}

\section{Study group}

Merianieae (Melastomataceae) are a Neotropical plant tribe of ca. 300 species, which has radiated recently in the tropical Andes (Dellinger et al. 2021). Bee pollination is ancestral and common both among lowland rainforest and cloud forest Merianieae, while shifts to vertebrate pollination $(3 \mathrm{x}$ passerine, $3 \mathrm{x}$ mixed assemblages of vertebrates) are restricted to cloud forest species (for detailed empirical pollinator obsevations, see Dellinger et al. 2014, 2019b, 2021). For this study, we chose six species: lowland rainforest bee-pollinated Adelobotrys adscendens (Sw.) Triana, cloud forest bee-pollinated Meriania maxima Markgr., passerine-pollinated Axinaea costaricensis Cogn., and three species pollinated by different combinations of vertebrates (M. phlomoides (Triana) Almeda and M. tomentosa (Cogn.) Wurdack, pollinated by hummingbirds and bats; M. sanguinea Wurdack, pollinated by hummingbirds, bats and rodents, Dellinger et al. 2019b). Our sampling covers three independent pollinator shifts from bee to vertebrate pollination (1: M. sanguinea, 2: M. tomentosa and M. phlomoides (part of the same subclade of Merianieae), 3. A. costaricensis ; Dellinger et al. 2019b). The six species differ in distribution ranges and ecosystems colonized (i.e. lowland rainforests, cloud forests, Fig. 1). Our approach of directly addressing these differences through landscape genetics and (historic) niche modelling allows us to objectively evaluate the multifarious factors potentially structuring population genetic diversity across multiple related species. Since all six species have similarly small, dry, wind-dispersed seeds, gene flow attributable to seed dispersal is comparable (and potentially limited to short distances given the dense structure of tropical forests, Kartzinel et al. 2013, Nazareno et al. 2020).

\section{Sample collection, GPS-coordinates and DNA extraction}

We collected leaf and bark material in silica gel and sampled five to six localities per species in Costa Rica (2015) or Ecuador (2016, 2017; Fig. 1, Table S1). To ensure comparability between species, we sampled at 
least two localities in close vicinity $(<12 \mathrm{~km}$ distance) and the other localities at larger distances $(>20 \mathrm{~km}$; Table S2). On average, we sampled 13 (sd 3) individuals per locality across a distance of one kilometer (Table S1). We recorded the exact location of each individual sampled to assess mating patterns within localities (Gelmi-Candusso et al. 2017) and calculated the centroid to obtain the average coordinate of each locality. We calculated Euclidean distances between localities based on these averaged coordinates in R (R Developmental Core Team 2019).

We extracted genomic DNA from ca. $60 \mathrm{mg}$ of dried plant material of 424 individuals using a CTAB protocol with sorbitol washing (Barfuss et al. 2016), RNAse treatment and subsequent clean-up (gDNA Cleanup Kit, Machery-Nagl). We quantified double stranded DNA content using the Qubit 3.0 Fluorometer with the dsDNA HS Assay Kit (Thermofisher) and only used samples with more than $6 \mathrm{ng} / \mu \mathrm{l}$ of DNA.

\section{Genome size estimation and RADseq library preparation}

For three species (Adelobotrys adscendens, Axinaea costaricensis, Meriania phlomoides ), we estimated genome sizes to select appropriate restriction enzymes for RADseq. We prepared fresh leaf material for three individuals per species in Otto's buffer (Otto et al. 1981) for propidium iodide flow cytometry (CyFlow ML flow cytometer, Partec, Münster, Germany; 532nm/100mW laser, Cobolt Samba, Cobolt AB, Solna, Sweden) following Temsch et al. (2010). We used Solanum pseudocapsicum $(1 \mathrm{C}=1.29 \mathrm{pg}$ DNA) as internal standard to calculate $1 \mathrm{C}$ values for each run (three runs per sample) and calculated the mean $1 \mathrm{C}$ per species over all runs and individuals. Average genome sizes (1C value) for the three species were estimated as follows: Ad. adscendens $0.344 \mathrm{pg}$, sd $0.003 ;$ A. costaricensis $0.587 \mathrm{pg}$, sd $0.01 ;$ M. phlomoides $0.639 \mathrm{pg}$, sd 0.006 . According to the Kew C-value database, these genome sizes are the second, third and fourth estimates for the family (Hanson et al. 2001).

In accordance with the relatively small genome sizes, we selected the restriction enzyme PstI (New England Biolabs, Ipswich, MA, USA) for single-digest RADseq (protocol modified from Paun et al. (2016)). We prepared eight RADseq libraries starting with $240 \mathrm{ng}$ DNA per sample, pooling 72 samples per library, including also some repeats (using $120 \mathrm{ng}$ DNA per sample). We ligated $300 \mathrm{nM}$ P1 barcoded adapters (150 nM if $120 \mathrm{ng}$ input DNA) to the restricted samples at $16^{\circ} \mathrm{C}$ overnight. The P1 adapters included both index and inline barcodes, that were different from each other by at least 3 nucleotide positions. After P1 ligation, we sheared the DNA by sonication in a Bioruptor Pico (Diagenode, Seraing, Belgium) using two cycles (45 seconds 'on', 30 seconds 'off'; at $4^{\circ} \mathrm{C}$ ) to obtain DNA fragments of $400 \mathrm{bp}$ on average. After P2 adapter ligation, PCR amplification and clean-up steps (using the MiniElute PCR purification Kit, Qiagen), we performed a final size selection for the range 220 to $850 \mathrm{bp}$ using a $1.5 \%$ precasted dye-free cassette and a Pippin Prep (Sage Science). All libraries were sequenced on an Illumina HiSeq 2500 machine at Vienna BioCenter Core Facilities (VBCF) (http://www.viennabiocenter.org/vbcf/next-generation-sequencing/) as $100 \mathrm{bp}$ single-end reads.

\section{Identification of RAD loci and variant filtering}

We demultiplexed the data to sublibraries (index barcodes) with BamIndexDecoder v.1.03 (included in Picard Illumina2Bam, available fromhttp://gq1.github.io/illumina2bam/), quality-filtered and further demultiplexed the reads to individual accessions (inline barcodes) using process_radtags.pl from STACKS v.1.47 (Catchen et al. 2013). We removed low-quality reads with an uncalled base and corrected inline barcodes and RADtags with one mismatch, retaining only full-length reads (94 bp). We concatenated samples which had been sequenced twice. As there is no reference genome available for Merianieae, we followed Brandrud et al. (2020) to first create a pseudo-reference using denovo_map.pl from STACKS and followed up with a mapping approach to improve coverage and the recovery of loci. For each of the six species, we selected the ten samples with the highest number of reads to be used for building a unique pseudo-reference. We built several catalogues using different settings and chose the best following the r80 rule of Paris et al. (2017) for parameter optimization. We tested $m$ (minimum number of identical reads required to create a stack) four and five, subsequently increased $M$ (number of mismatches between stacks within individual) starting from one, and $n$ (number of mismatches allowed between stacks between individuals) as $n=M$ or $n=M+1$ 
(Paris et al. 2017). For each setting, we recorded the number of tags retained with data for at least $80 \%$ of individuals and chose the settings $m 4, M 1$ and $n 2$ which gave the maximum number of reliable polymorphic loci. We extracted the fasta pseudo-reference from the optimized catalogue by including polymorphic RAD loci that were present in at least $30 \%$ of samples and contained up to nine SNPs using export_sql.pl from STACKS. We then mapped the raw reads of each accession to this pseudo-reference separately using the mem algorithm of BWA v.0.7.12-5 (Li \& Durbin 2009), flagging shorter split hits as secondary (-M). Next, we sorted the resulting aligned sam-files by reference coordinates and added read groups in the output .bam-files with Picard Tools v.2.18.17 (Wysoker et al. 2013). Finally, we performed a realignment around indels using the Genome Analysis Toolkit v.3.8.1 (GATK; McKenna et al. 2010).

The six species compared in this study are not equally closely related. Specifically, Adelobotrys adscendens, the lowland bee-pollinated species, is part of a clade that diverged from core Merianieae (where the other five species belong to) approximately 25 million years ago (Dellinger et al. 2021). Whereas the common pseudoreference we used for mapping should be appropriate for the five core Merianieae species, ascertainment bias may affect the inference for $A d$. adscendensbased on this reference. To address this issue, we tested whether the mapping rates for the six study species to the pseudo-reference differ significantly from each other using ANOVA and Tukey-tests as post-hoc tests. Indeed, the mapping rate of Ad. adscendens was significantly lower than of all other species $(\mathrm{F}=86.31, \mathrm{df}=5, \mathrm{p}<0.01$; for pairwise-comparisons see Table S3). We hence decided to create a separate pseudo-reference for $A d$. adscendens, based on its own accessions only, following the optimization procedure described above (final settings used are $\mathrm{m} 5, \mathrm{M} 6, \mathrm{n} 6$ ). Using this approach, we increased the mapping rate for Ad. adscendens from $31.7 \%$ to $35.1 \%$ (Table S4; the reference includes only polymorphic loci). We treated $A d$. adscendens the same way as all other species in subsequent analyses unless otherwise stated.

\section{Mating patterns: population genetic summary statistics}

We measured genetic diversity within localities by calculating per-site nucleotide diversity $\left(\vartheta_{\pi}\right.$, i.e. average number of pairwise differences between sequences) using ANGSD. We generated a theta file for each locality based on the locality-specific site frequency spectra. We intersected the theta files of all localities of each species in order to only compare SNPs that were shared by all localities following Peñalba et al. (2015). From these intersected sites files, we calculated nucleotide diversity using thetaStat as implemented in ANGSD (Maas et al. 2018). We divided $\vartheta_{\pi}$ estimates by the number of sites and tested for significant differences between localities using Kruskal-Wallis ANOVA and Dunn tests with Bonferroni correction for multiple comparisons (Dinno 2017). For calculating heterozygosity, we calculated unfolded site frequency spectra per individual and divided per-individual heterozygosity by the total number of sites. Again, we used KruskalWallis ANOVA and Dunn tests to evaluate differences among localities.

We calculated per-individual inbreeding coefficients $(F)$ on genotype likelihoods as the degree of deviation from Hardy-Weinberg equilibrium (ngsF v.1.2.0-STD, Vieira et al. 2013). We performed two runs in ngsF, the first run to calculate reliable starting values of $F$ per individual and a second performing a deeper search, allowing for a maximum of 1,500 iterations.

We assessed localized (within locality) mating patterns by testing for isolation-by-distance (IBD) between individuals using Mantel's tests on pairwise genetic distances (calculated using ngsDist v.1.0.9, Vieira et al. 2016b) and log-transformed geographic distances between individuals (mantel.randtest, 10,000 permutations, ADE4 v.1.7-13; Dray \& Dufour 2007).

\section{Population structure: genetic differentiation and disparity}

To visualize population clustering, we used principal component analyses (PCA), starting from genotypefrequency-based covariance matrices (pcangsd v.0.99, Meisner \& Albrechtsen 2018). We further visualized coancestry between individuals for each species using heatmaps (GPLOTS v.3.0.1.1; Warnes et al. 2020).

We used two measures of genetic distance to test whether populations were significantly different from each other. First, we converted pcangsd-derived covariance matrices to distance matrices (dist.from.cov , 
rwc v.1.11; Hanks 2018). Second, we calculated pairwise genetic distances between all individuals of each species (ngsDist). We then tested for significant differences in genetic diversity between populations of the same species (adonis, VEGAN; Oksanen et al. 2019). We used pairwise.adonis (with corrected p-value estimation) as post-hoc test to assess which populations were significantly different. In order to test whether certain populations were more disparate (genetically variable) than others, we usedbetadisper and TukeyHSD as post-hoc test (results presented in SI).

In order to assess population genetic differentiation, we calculated $F_{S T}$ values on genotype likelihoods starting from unfolded, pairwise SFS (core Merianieae) or folded SFS (Ad. adscendens ) using realSFS in ANGSD.

We further calculated the admixture coefficient for each individual by estimating the likelihood of genetic clustering in the data (NGSadmix, Skotte et al. 2013). We randomly selected only one SNP per locus and used ten random initializations to estimate admixture from $K=1$ to $K=n+1$ ancestral populations, $n$ being the total number of sampled localities in each species. We compared the rate of change in the log-likelihood of different successive K-values (Evanno 2005) to select the K-value best describing clustering in the data and used bar plots for visualization.

Testing for the isolating effects of distance, terrain, current and historic climatic suitability and environmental niche

We used landscape genetic approaches to estimate the degree of connectivity among localities, assessing the relative impact of isolating barriers ( $\mathrm{IBR}_{\text {Terrain }}$, based on topographic complexity), current climatic suitability ( $\mathrm{IBR}_{\text {Habitat }}$, based on environmental niches), climatic suitability since the LGM (IBI - isolationby-instability) and the environmental niche (IBE) on population genomic differentiation $\left(F_{S T}\right)$. For each species, we downloaded occurrence data from GBIF (Table S5; Chamberlainet al ., 2021, Fig. S1) and pruned the data using custom cleaning techniques (COORDINATECLEANER, Zizka et al. 2019), flagging records with equal longitude/latitude, zero coordinates, coordinate-country mismatches, records located in country centroids, in the sea or around GBIF headquarters as well as duplicates and altitudinal outliers. To estimate $\mathrm{IBR}_{\text {Terrain }}$, we used raw elevation data (30 arc-sec resolution, earthenv.org/topography) and calculated topographic complexity using the Terrain Ruggedness Index (TRI, tri function, SPATIALECO, Evans 2021). For each species, we drew convex hulls around GBIF occurrences with a $0.4^{\circ}$ buffer (RGEOS, Bivand \& Rundel 2020) and assessed each species' elevational distribution range (Table S5). Within the convex hulls, we restricted the TRI layer to the plausible altitudinal distribution range of each species by removing areas 100 masl below and above the lowest and highest GBIF occurrence (mask, RASTER; Table S5). To define a resistance cost surface based on TRI, we chose cost values to represent different proportions of the GBIF occurrences, with 1 (low cost) representing the central $70 \%$ of the GBIF occurrences of each species, 2 (moderate cost) representing the adjacent $5 \%$ quantiles (10\%-15\% and 85\%-90\%), 4 (high cost) representing the next 5\% quantiles (5\%-10\% and 90\%-95\%), 8 (very high cost) representing the 0\%-5\% and 95\%-100\% quantiles, and 16 (extremely high cost) representing TRI values outside of the range covered by actual GBIF occurrences. Next, we calculated a transition object specifying a 'knight and one-cell queen move' direction (transition, GDISTANCE, van Etten 2017) and correcting for map distortion (geoCorrection ). Finally, we calculated all pairwise least-cost distances (paths with least-accumulative cost over cost surface) between the sampling localities (costDistancefunction).

To estimate $\mathrm{IBR}_{\text {Habitat }}$, we selected four bioclimatic variables relevant for tropical plants: Annual Mean Temperature (bio1), Mean Diurnal Temperature Range (bio2), Annual Precipitation (bio12), Precipitation Seasonality (bio15; WorldClim 2.0, 30 arc sec, Fick \& Hijmans 2017). We restricted these rasters as we did for $\mathrm{IBR}_{\text {Terrain }}$ and estimated the abiotic climatic niche of each species using all GBIF occurrences using MaxEnt 3.4.1 (DISMO, Hijmans et al. 2020). We created 10000 pseudo-absence points (the default number of background points used by MaxEnt) from raster cells lacking GBIF occurrences (DISMO, Hijmans et al. 2020). We set $80 \%$ of the GBIF occurrences of each species as training dataset and $20 \%$ to validate the models, using 500 iterations. We fit models 10 times and validated model fit using AUC (area under the receiver operating curve, values $>0.75$ indicate good fit, Swets 1988) and TSS (true skill statistic, values range between -1 and $+1 ;-1$ to 0 -no better than random; values $>0.4-0.8$ acceptable models, see Ornelas 
et al. 2019, Table S6; SDMtune, Vignali et al. 2020). In addition, we evaluated model performance using fourfold spatial-block cross-validation (blockCV, Valavi et al. 2019). In this approach, the occurrence dataset is split into four spatially distinct blocks, which are used as training datasets separately and subsequently used to test how well a model can be transferred to environmental space not used for calibration (Table S6). After assuring good model performance, we created raster maps of habitat suitability $(0-0 \%$ suitable, 1 - $100 \%$ suitable) and averaged all ten models. To arrive with a resistance cost surface, we subtracted the climatic niche raster from 1 so that 0 means low cost and 1 means high cost. We then calculated the transition object as for $\mathrm{IBR}_{\text {Terrain }}$ and calculated all pairwise least-cost distances between the sampled localities.

To estimate IBI, we used the same four bioclimatic variables (bio1, bio2, bio12, bio15, at 2.5 arc min resolution) as for the current climate, but derived from three different general circulation models for the LGM and mid-Holocene (NCAR-CCSM4, MIROC-ESM, MPI-ESM-P, WorldClim 1.4, Hijmans et al. 2005). Since substantial downward shifts in elevation zones may have occurred during the LGM (Ramírez-Barahona \& Eguiarte 2013), we set the lower elevation restriction to zero in all species and kept the upper elevation restriction (see above). To minimize errors of temporal extrapolation from current to past niche models, we ran Multivariate Environmental Similarity Surface analyses (MESS) in DISMO (Figure S2, Elith et al. 2010). If past environments encompass climatic conditions not found in the training dataset, MESS will give negative values. High dissimilarity (many negative values) is limiting the predictive accuracy of models and hence identifies scenarios/areas where model results need to be treated with particular care. For each species, we calculated MESS for each past circulation model (Figure S2). Dissimilarity was overall low in all species but $M$. sanguinea, and the MIROC-ESM circulation model showed highest dissimilarity across all species (Fig. S2). We hence excluded MIROC-ESM from subsequent analyses.

For estimating habitat stability, we first estimated the current abiotic climatic niche of each species as for $\mathrm{IBR}_{\text {Habitat }}$, and then projected current habitat suitability to the LGM and mid-Holocene. We fit each model 10 times and averaged habitat suitability across runs and circulation models. Next, to derive a measure of habitat suitability through time, we overlaid the suitability maps of the three times (current, mid-Holocene, LGM) and averaged suitability of each raster cell. A raster cell providing $100 \%$ suitable conditions at all three times hence received a value of 1 , while a raster cell providing unsuitable conditions at all three times received a value of 0 . Again, we subtracted the suitability raster by 1 to arrive with a resistance cost surface and calculated all pairwise least-cost distances between localities of each species (see above; Fig. S3).

Finally, we calculated isolation-by-environment (IBE) by extracting the raw values of the four bioclimatic variables (current climate) per population and calculating the Euclidean distances in environmental space between sampled localities using the dist function in $\mathrm{R}$.

Naturally, the resistance surfaces we calculated for $\mathrm{IBR}_{\text {Terrain }}, \mathrm{IBR}_{\text {Habitat }}$ and IBI represent refined geographic matrices and may thus be strongly correlated to the Euclidean geographic IBD matrices. We hence first ran separate Mantel tests (with 10,000 permutations) on these four matrices (each matrix standardized by the mean to account for differences in scale) to assess collinearity (García-Rodríguez et al. 2020). The four matrices were strongly correlated in most species (Table S7). We hence next constructed separate Mantel tests (with 10,000 permutations) to test for the effect of the respective distance matrix on normalized population genetic differentiation $\left(F_{S T} /\left(1-F_{S T}\right)\right)$. Then, for each species, we selected the distance measure with the highest $\mathrm{R}^{2}$ and used multiple matrix regressions with randomizations (10,000 random permutations, Wang 2013) to test for the relative impact of the respective distance matrix and IBE on population genetic differentiation using rglMMRR (POPGENREPORT, Adamack \& Gruber 2014).

Given recent criticism on the use of multiple matrix regressions (inflation of degrees of freedom, weak correlations may receive significant p-values (Moncada et al. 2020)), we additionally implemented Generalized Dissimilarity Modelling (GDM). GDM is a multivariate procedure allowing for modelling a single response variable as a function of any number of explanatory variables (Manly 1986) and allows for non-linear relationships among the response and explanatory variables using I-spline functions (Ferrier et al. 2007). For each species, we fit a GDM, specifying $F_{S T}$ as response and IBD plus the resistance matrices and IBE as explanatory variables using the R-package gdm (Fitzpatrick et al. 2020). We plotted I-splines to visualize 
how magnitudes and rates of genetic differentiation vary with explanatory variables and estimated the (combination of) explanatory variable(s) best explaining genetic differentiation using backward elimination with permutation (see Ferrier et al. 2007, García-Rodríguez et al. 2020 for recent implementation). Briefly, the unique contribution of each predictor variable to total explained deviance is calculated, and the variable least contributing is discarded before fitting a new GDM. We ran 500 permutations until all variables retained in the final model made significant $(\mathrm{p}<0.05)$, unique contributions to the explained deviance.

\section{Results}

\section{Genomic datasets}

The average number of high-quality reads retained per accession after demultiplexing ranged between $737 \mathrm{~K}$ and 2,008K (Table S4). The final pseudo-references included 30,791 (Ad. adscendens ) and 77,720 polymorphic loci (core Merianieae). The average mapping rates ranged between $35.1 \%$ and $54.3 \%$, with a coverage of 5.7x to 16.8x (Table S4). After filtering, we retained 197,868 to 380,588 variant sites per species (Table S4).

\section{Mating patterns and within-population IBD}

Population nucleotide diversity $\vartheta_{\pi}$ across all sites ranged between 0.0006 and 0.0073 and was variable among species (Fig. 2a, Tables S8, S9). Per species average estimates were lowest for bee-pollinated Ad. adscendens and highest for hummingbird-bat-pollinated M. tomentosa (Table S8). We detected significant differences in $\vartheta_{\pi}$ both among adjacent and distant localities in all species (Tables S9, S10).

Heterozygosity was most variable in bee-pollinated $A d$. adscendens(Fig. 2b) and least variable in vertebratepollinated M. tomentosa (Fig. 2b). We detected significant differences in heterozygosity among localities in all species but vertebrate-pollinated $A$. costaricensis and $M$. sanguinea (Table S11, S12). Overall, only few localities differed significantly in heterozygosity (Table S12).

Per individual inbreeding coefficients $(F)$ were generally low for all species (Fig. S4, Table S13). Eleven individuals of $A d$. adscendens showed intermediate to high levels of inbreeding $(F 0.05-0.5)$, followed by $M$. sanguinea (one individual) while all other species had lower $F$ values (Table S13).

Within localities, there was inconsistent isolation-by-distance (Table S14). Geographic and genetic distances between individuals correlated significantly in three out of six localities in bee-pollinated Ad. adscendens , in two out of five localities in bee-pollinated M. maxima, and in one locality each of vertebrate-pollinated M. phlomoides, M. tomentosa and A. costaricensis. There was no significant IBD within localities in $M$. sanguinea .

\section{Population structure and disparity}

Population structuring was variable between species and clustering mostly reflected geographic relationships (Fig. 3, Fig. S5). Individuals of lowland bee-pollinated Ad. adscendens grouped into two distinct clusters (South-Western versus Northern Costa Rica, Fig. 1A, Fig. 3A). While admixture analyses supported two ancestral populations with low admixture, co-ancestry estimates revealed shared co-ancestry between the two geographic clusters (Fig. 3A). In bee-pollinatedM. maxima, individuals clustered into three distinct groups (Fig. 3B) despite relative geographic vicinity among all localities (Fig. 1). Admixture analyses detected three ancestral populations with low admixture (below 10\%) and were supported by co-ancestry estimates (Fig. 3B). We also detected population clustering in hummingbird-bat-rodent-pollinated M. sanguinea (two clusters, Fig. 3D) and in hummingbird-bat-pollinated M. tomentosa (three clusters, Fig. 3E), representing distant localities in Northern and Southern Ecuador (Fig. 1). Admixture was mostly below $20 \%$ in both species, with highest probability of two ancestral populations, and low co-ancestry between the geographic clusters (Fig. 3D, E). Population structuring was weak and admixture high (ca. 30\%) in hummingbirdbat-pollinated M. phlomoides (Fig. 3C) and passerine-pollinated A. costaricensis (Fig. 3F). We found highest likelihood for three ancestral populations in M. phlomoides, and two ancestral populations in $A$. costaricensis, and overall high shared co-ancestry across localities (Fig. 3C, F, Fig. S5). 
In all species, at least some localities were significantly differentiated from each other (Tables S15, S16), but adjacent localities were generally not differentiated (Fig. 1). Genetic differentiation was weakest in passerine-pollinated A. costaricensis and highest in bee-pollinated $A d$. adscendens. We detected most significant differences in genetic disparity among localities in $A d$. adscendens (6/15 comparisons) and $M$. tomentosa (4-5/10 comparisons) and no differences in M. sanguinea and A. costaricensis (Table S17, S18). Compared to the other species, montane bee-pollinated M. maxima showed lowest disparity within localities (Fig. S5).

\section{Isolation-by-distance, resistance, instability and environment}

Pairwise population fixation indices $\left(F_{S T}\right)$ confirmed patterns found in admixture and co-ancestry analyses and indicated moderate to high population structuring, ranging from 0.0178 (adjacent localities 1 and 2 of M. maxima ) to 0.661 (distant localities 1 and 6 of Ad. adscendens ; Fig. 1, Table S2). On average, across all localities in each species, $A$. costaricensisshowed lowest $\left(F_{S T}=0.123\right)$ and Ad. adscendens highest genetic differentiation $\left(F_{S T}=0.422\right)$. Comparing the two adjacent localities in each species, we found lowest $F_{S T}$ in bee-pollinated M. maxima (0.018) and highest in passerine-pollinated A. costaricensis (0.105, Fig. 1).

Mantel's tests on normalized $F_{S T}$ revealed that, in all species, population differentiation strongly associated with geographic distance (IBD, Table 1, Fig. 4). Associations were significant in all species but $A$. costaricensis $\left(\mathrm{R}^{2} 0.75, \mathrm{p}=0.055\right)$. In vertebrate-pollinated M. phlomoides, M. sanguinea ,M. tomentosa, and A. costaricensis , $F_{S T}$ also correlated most strongly with geographic distance (IBD). In bee-pollinated Ad. adscendens, correlation was strongest (but not significant) with geographic barriers $\left(\mathrm{IBR}_{\text {Terrain }}\right)$ and historic habitat suitability (IBI, $\mathrm{R}^{2} 0.796, \mathrm{p}=0.048$ ), while in $M$. maxima , $F_{S T}$ associated most strongly with current climatic suitability $\left(\mathrm{R}^{2} 0.777, \mathrm{p}=0.023\right.$, $\left.\mathrm{IBR}_{\text {Habitat }}\right)$. In all species but $A$. costaricensis, we also detected a significant correlation with Pleistocene climatic instability (IBI, Table 1, Fig. S3, S6, S7). We did not detect any significant correlation with environmental distances (IBE, Fig. 3, Table 1). These patterns

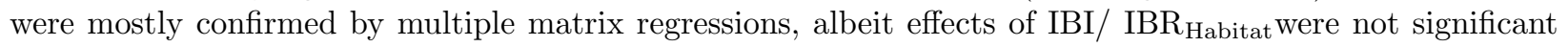
in A. adscendens and M. maxima, respectively (Table S19).

These results were mostly confirmed by GDM (Table 2, Table S20 details model fit). In bee-pollinated $A d$.

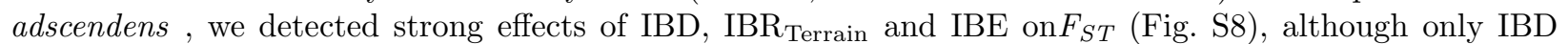
was retained as significant in the final model (Table 2). In bee-pollinated M. maxima, we found significant effects of current habitat suitability $\left(\mathrm{IBR}_{\text {Habitat }}\right)$ and IBD (Table 2, Fig. S9). $F_{S T}$ in hummingbird-batrodent-pollinated $M$. sanguinea and hummingbird-bat-pollinated M. phlomoides was significantly affected only by geographic distance (IBD, Table 2 , Fig. S10, S11), while $F_{S T}$ in hummingbird-bat-pollinated and $M$. tomentosa was most strongly affected by climatic instability since the LGM (IBI) and IBD (Table 2, Fig. S12). In A. costaricensis, again, no variable significantly affected $F_{S T}$ (Table 2, Fig. S13).

\section{Discussion}

Analysing the multifarious factors potentially generating population differentiation across six related Neotropical plant species differing in pollination strategy, we here detected consistently stronger isolating effects (particularly IBD) across localities of bee- than vertebrate-pollinated species (Table 1, Fig. 4). The two bee-pollinated species were the only ones where current climatic conditions contributed substantially to explaining population differentiation. These results are in line with the expectation that more mobile pollinators (i.e. flying vertebrates) may connect populations more effectively than less mobile (i.e. (small) bee) pollinators (Wessinger 2021). Even though large bees (pollinators of M. maxima) are generally considered as relatively mobile (Gamba \& Muchhala 2020), their flight activity is strongly reduced under adverse weather conditions in tropical mountains, likely limiting (large-distance) pollen dispersal (Dellinger et al. 2021). Within localities, we also detected IBD more frequently in bee- than vertebrate-pollinated localities (Table S14). Against expectations, however, we did not find consistent differences in nucleotide diversity, heterozygosity or disparity according to pollination strategy (Fig. 2). This suggests that, at least across small spatial scales (i.e. within localities, between adjacent localities), bees may be equally effective outcross pollinators as vertebrates (Opedal et al. 2017, Schmidt-Lebuhn et al. 2019). In the following, we discuss our 
findings in the context of other factors potentially influencing present-day population genetic structure such as mountain topography, habitat suitability and Pleistocene climatic fluctuations.

Our study species share the same macroevolutionary background (same tribe), but differ in distribution ranges and ecosystems colonized. Bee-pollinated Ad. adscendens has a wide distribution in lowland rainforests in tropical Latin America, while the other five species inhabit montane cloud forests with relatively continuous (M. phlomoides, M. tomentosa) or patchy (A. costaricensis, M. maxima, M. sanguinea) distributions (Fig. S1). We may, hence, expect partly idiosyncratic responses to isolating barriers and (current and past) climatic habitat suitability. Following the expectation that mountain terrain generates strong physical barriers, we did indeed detect significant $\mathrm{IBR}_{\text {Terrain }}$ in all species but $A$. costaricensis (Table 1). It was, however, never recovered as factor best explaining population differentiation (Tables 2). While rugged mountain terrain may act as effective barrier even across small spatial scales (i.e. populations three and six in M. phlomoides , Fig. 1), admixture was overall high among close $(<12 \mathrm{~km})$ localities in all species, suggesting considerable connectivity by both insect and vertebrate pollinators among localities (Fig. 3).

Ectothermic insect pollinators may be affected more strongly by harsh abiotic climatic conditions (i.e. low temperatures, high precipitation, strong winds) than vertebrate pollinators (Cruden 1972, Dellinger et al. 2021). Accordingly, we found evidence of isolating effects related to current climatic conditions (Table 2, Fig. 4) only in the two bee-pollinated species (IBE in $A d$. adscendens and $\mathrm{IBR}_{\text {Habitat }}$ in M. maxima). In Ad. adscendens, the marked separation into two clusters (Fig. 1A, 3A) clearly reflects the combination of IBD, isolating effects related to mountain topography, and current climatic conditions. The south-western localities are cut off from the north-eastern localities by the central Costa Rican mountain range. These mountains feature moist and cool cloud forests, which are generally unhostile to smaller bees, the pollinators of Ad. adscendens (Dellinger et al. 2019). Along the western coast, occasional dry habitats (i.e. Nicoya peninsula), on the other hand, represent unsuitable habitats for the moisture-adapted plants (Pröhl et al. 2010). In accordance with this, our niche models estimated the 'least-cost' path connecting the southern and northern localities of Ad. adscendens through the south-eastern lowlands along the Caribbean side of the high Central American mountains (Fig. 1A, Patten \& Smith-Patten 2008). In M. maxima, the marked differentiation among localities 3 and 4 may further indicate disproportionately strong effects of climatic conditions on ectothermic bee-pollinator activity. These two localities were significantly differentiated from each other genetically, albeit only $20 \mathrm{~km}$ apart. Our habitat-suitability models indicated that locality 4 lies in a climatically less suitable area (Fig. 1). Our own experimental work in montane Meriania species in the Andes has established a strong link between bee pollinator activity and current weather conditions, with high bee activity under sunny conditions, but almost no flower visitation under cool and rainy conditions (Dellinger et al. 2021). It is hence possible that the difference in habitat suitability strongly reduced the probability of bee flight among these localities, hence generating strong population differentiation. Interestingly, we also found individuals of M. maxima in locality 4 to differ morphologically (i.e. smaller flowers, non-revolute leaf basis, Dellinger, pers. obsv.). Whether these observed phenotypic differences are the result of random genetic drift, or a response to different selection pressures, remains to be investigated.

Among the vertebrate-pollinated species, we did not find isolating effects caused by habitat suitability $\left(\mathrm{IBR}_{\text {Habitat }}\right)$ or environment (IBE; Fig. 1, Table 2). Indeed, cloud forests form a relatively continuous ecosystem particularly on the eastern slopes of the Andes and Central American mountains (Balslev 1988, Luebert \& Weigend 2014), and possibly provide continuously suitable habitats for the cold-adapted vertebrate pollinators. The marked population differentiation observed between Northern and Southern Ecuadorian populations of $M$. sanguinea and $M$. tomentosa, on the other hand, follows the well-known biogeographic barrier of the dry Girón-Paute valley (Jørgensen \& Ulloa Ulloa 1994, Escobar et al. 2020). This demarcation line, part of the Amotape-Huancabamba zone, has acted both as dispersal barrier for montane species as well as a corridor for lowland species (Weigend 2002, Trénel et al. 2008).

Understanding how tropical plants reacted to Pleistocene climatic fluctuations, i.e. whether they retracted into refugia ('dry-refugia' hypothesis) or underwent down- and upslope migrations ('moist-forest' hypothesis), remains a major conundrum (Ramírez-Barahona \& Eguiarte 2013). If species retracted into small refugia, 
climatic instability through time should explain population genetic variation (Helmstetter et al. 2020). In our study, we found significant associations between genetic differentiation and climatic instability in five species (Table 1), but IBI was recovered as factor best explaining variation in $F_{S T}$ only in $M$. tomentosa . Indeed, modelling past climatic habitat suitability indicated that the cloud forest species A. costaricensis, $M$. maxima, $M$. phlomoides and $M$. tomentosa retained relatively continuous suitable habitats along the Central and Northern South American mountain ranges throughout the Pleistocene (Fig. S3). These results support the 'moist-forest' hypothesis, with downslope and subsequent upslope migration during Pleistocene climatic fluctuations (Fig. S14), and even range expansion in M. phlomoides (Fig. S3c). Further, at the scale of our study localities, there was some evidence of habitat contraction during the LGM in A. costaricensis (continuously suitable around locality 4, Fig. S6) and M. maxima (continuously suitable around localities 1, 2 and 5, Fig. S7). This suggests the possibility for in-situ persistence of these cloud-forest species in part of the distribution range (without necessarily contraction into isolated refugia), a pattern documented for other montane Neotropical plant lineages (Ornelas et al. 2019). M. sanguinea, on the other hand, is the only species in our sample occurring in the high-elevation cloud-forest-Páramo-ecotone. This species may have undergone more prominent refugial retraction in Southern Ecuador and Peru (Fig. S3, S14). Indeed, our models indicate little connectivity among the southern Ecuadorian localities (south of the biogeographic barrier of the Amotape-Huancabamba zone) and markedly differentiated Northern Ecuadorian locality during the LGM (Fig. S7). Finally, in lowland bee-pollinated Ad. adscendens, suitable habitats were likely extensive in lowland Amazonia during the LGM, with mostly continuously suitable habitats along the (eastern) coast of Central America (Fig. S6, Pröhl et al. 2010).

Taken together, our results are highly valuable in adding to the limited data available on the diverse processes shaping population genetic differentiation of tropical plants, including differences in pollination strategy. While we highlight that a wider sampling across bee-pollinated Merianieae is required to firmly nail the role of pollinators in promoting population differentiation, our result on stronger isolation among bee- than vertebrate-pollinated populations suggests a critical role of pollinator mobility in shaping population-level processes. Extrapolating to a macroevolutionary perspective, pollinator shifts are often invoked as "key innovations" spurring diversification (van der Niet et al. 2014). Potentially, pollinator shifts may also alter a population's susceptibility to isolation and, consequently, its potential for allopatric divergence. Interestingly, in various Neotropical/Andean plant groups, shifts from bee to vertebrate (particularly hummingbird) pollination go hand in hand with increases in diversification rates (e.g. Serrano-Serrano et al. 2017, Lagomarsino et al. 2017). This is somewhat counter intuitive, however, if vertebrates are expected to buffer isolating effects among populations (see Serrano-Serrano et al. 2017 for discussion on additional factors). Clearly, comparative studies, ideally focusing on small monophyletic plant complexes, and documenting both pollination ecology and population genetics of multiple populations across the landscape (e.g. Opedal et al. 2017), will be essential for resolving the relative contribution of pollinator shifts in spurring or limiting speciation through gene flow (Abrahamczyk et al. 2014). To date, we largely lack pollinator observations from multiple populations of the same plant species in the (Neo)tropics, and hence know little about the variability of pollinator composition across a species' distribution range (pollinator mosaic, Gowda \& Kress 2013). Within our own dataset, we have such information for a subset of all populations only (Table S1). While we documented the same functional groups acting as pollinators in most populations, we documented effective hummingbird and rodent pollinators in Southern Ecuadorian populations of $M$. sanguinea, and hummingbird and bat pollinators in Northern Ecuador. Obtaining such natural history information, in addition to population genomic data, will be key for adding a more realistic understanding to the processes governing speciation and hence contributing to the exceptional diversity observed in the (Neo)tropics today.

\section{Acknowledgements}

We thank Francisco Sornoza, Silvia Artuso and Lisa Scheer for support with sample collection, Melania Muñoz and Rocio Pérez-Barrales for support in obtaining collection permits, and the following biological reserves for logistic support, forest preservation and lodging: Costa Rica: Monteverde Cloudforest Reserve, Monteverde Biological Station, Tropical Field Station La Gamba, Cerro Dantas, Finca Truchas Selva Madre, National Parks (Braulio Carillo, Chirripó, Volcán Tenorio, Piedras Blancas, La Amistad); Ecuador: Bellavista 
Cloudforest Reserve, EcoMinga foundation, Yocotoco foundation, Podocarpus National Park. Further thanks to Jacqueline Heckenhauer for help with DNA extractions and to Adrián García-Rodríguez for discussions on and scripts for GDM-analyses. This work was funded by FWF 30669-20 to ASD and JS and FWF-1186 to ASD.

\section{Literature}

Abrahamczyk S, Souto-Vilarós D, Renner SS. 2014. Escape from extreme specialization: passionflowers, bats and the sword-billed hummingbird. Proc. R Soc B 281: 20140888.

Adamack, A.T., Gruber, B. 2014. PopGenReport: simplifying basic population genetic analyses in R. Met Ecol Evol, 5, 384-387.

Ballesteros-Mejia, L., Lima, N.E., Lima-Ribeiro, M.S., Collevatti, R.G. 2016. Pollination mode and mating system explain patterns in genetic differentiation in Neotropical plants. PlosOne, 12, e0184674.

Balslev, H. 1988. Distribution patterns of Ecuadorean plant species. Taxon, 37, 567-577.

Barbará, T., Martinelli, G., Fay, M.F., Mayo, S.J., Lexer, C. 2007. Population differentiation and species cohesion in two closely related plants adapted to neotropical high-altitude 'inselbergs', Alcantarea imperialis and Alcantarea geniculata(Bromeliaceae). Mol. Ecol., 16, 1981-1992.

Barfuss, M.H.J., Till, W., Leme, E.M.C., Pinzon, J.P., Manzanares, J.M., Halbritter, H., et al . 2016. Taxonomic revision of Bromeliaceae subfam. Tillandsioideae based on a multi-locus DNA sequence phylogeny and morphology. Phytotaxa, 279, 1-97.

Bawa, K.S. 1992. Mating systems, genetic differentiation and speciation in tropical rain forest plants. Biotropica, 24, 250-255.

Bivand, R., Rundel, C. 2020. rgeos: Interface to Geometry Engine - Open Source ('GEOS'). R package version $0.5-5$.

Brandrud, M.K., Baar, J., Lorenzo, M.T., Athanasiadis, A., Bateman, R.M., Chase, M.W., et al. 2020. Phylogenomic relationships of diploids and the origins of allotetraploids in Dactylorhiza . Syst. Biol. 69, 91-109.

Breed, M., Ottewell, K.M., Gardner, M.G., Marklund, M.H.K., Dormontt, E.E., Lowe, A.J. 2015. Mating patterns and pollinator mobility are critical traits in forest fragmentation genetics. Heredity, 115, 108-114.

Carnaval, A.C., Hickerson, M.J., Haddad, C.F.B., Rodrigues, M.T., Moritz, C. 2009. Stability predicts genetic diversity in the Brazilian Atlantic Forest hotspot. Science, 23, 785-789.

Castilla, A.R., Pope, N.S., O’Connell, M., Rodriguez, M.F., Treviño, L., Santos, A., et al . 2017. Adding landscape genetics and individual traits to the ecosystem function paradigm reveals the importance of species functional breadth. PNAS, 48, 12761-12766.

Catchen, J., Hohenlohe, P.A., Bassham, S., Amores, A., Cresko, W.A. 2013. Stacks: an analysis tool set for population genomics. Mol Ecol, 22, 3124-3140.

Chamberlain, S., Barve, V., Mcglinn, D., Oldoni, D., Desmet, P., Geffert, L., et al . 2021. Rgbif: Interface to the Global Biodiversity Information Facility API. V. 3.5.2. URL http://CRAN.Rproject.org $/$ package $=$ rgbif.html

Clavino-Cancela, M., Escudero, M., Rodriguez-Perez, J., Cano, E., Vargas, P., Vele-Antón, G., et al . 2012. The role of seed dispersal, pollination and historical effects of genetic patterns of an insular plant that has lost its only seed disperser. J. Biogeo . 39, 1996-2006.

Cortés, A.J., Garzón, L.N., Valencia, J.B., Madrinán, S. 2018. On the causes of rapid diversification in the páramos: isolation by ecology and genomic divergence in Espeletia . Fornt. Plant Sci . 9, 1700. 
Dellinger, A.S., Penneys, D.S., Staedler, Y.M., Fragner, L., Weckwerth, W., Schönenberger, J. 2014. A specialized bird pollination system with a bellows mechanism for pollen transfer and staminal food body rewards. Curr. Biol., 24, 1615-1619.

Dellinger, A.S., Chartier, M., Fernández-Fernández, D., Penneys, D.S., Alvear, M., Almeda, F., et al. 2019a. Beyond buzz-pollination - departures from an adaptive plateau lead to new pollination syndromes. New Phytol., 221, 1136-1149.

Dellinger, A.S., Scheer, L.M., Artuso, S., Fernández-Fernández, D., Sornoza, F., Penneys, D.S., et al. 2019b. Bimodal pollination systems in Andean Melastomataceae involving birds, bats and rodents. Am. Nat., 194, 104-116.

Dellinger, A.S., Pérez-Barrales, R., Michelangeli, F.A., Penneys, D.S., Fernández-Fernández, D.M., Schönenberger, J. 2021. Low bee visitation rates explain pollinator shifts to vertebrates in tropical mountains. New Phytol, 231, 864-877.

Dellinger, A. S., Paun, O., Baar, J., Temsch, E.M, Fernández-Fernández, D., Schönenberger, J. 2021. Dataset for Population structure in Neotropical plants. https://phaidra.univie.ac.at/o:1368440

Dinno, A. 2017. dunn.test: Dunn's Test of Multiple Comparisons Using Rank Sums. R package version 1.3.5. https://CRAN.R-project.org/package=dunn.test

Dray, S., Dufour, A. 2007. "The ade4 Package: Implementing the Duality Diagram for Ecologists." J. Stat. Software, 22, 1-20.

Escobar, S., Helmstetter, A.J., Jarvie, S., Montúfar, R., Balslev, H., Couvreur, T.L.P. 2020. Pleistocene climatic fluctuations promoted alternative evolutionary histories in Phytelephas aequatorialis, an endemic palm from western Ecuador. J Biogeo, 48, 1023-1037.

Evanno, G., Regnaut, S., Goudet, J. 2005. Detecting the number of clusters of individuals using the software structure: A simulation study. Mol. Ecol., 14, 2611-2620.

Evans, J.S. 2021. spatialEco . R package version 1.3-6,https://github.com/jeffreyevans/spatialEco .

Fick, S.E. and R.J. Hijmans, 2017. WorldClim 2: new 1km spatial resolution climate surfaces for global land areas. International Journal of Climatology 37 (12): 4302-4315.

Fitzpatrick, M.C., Mokany, K., Manion, G., Lisk, M., Ferrier, S., Nieto-Lugilde, D. 2021.

gdm: Generalized Dissimilarity Modeling. $\mathrm{R}$ package version 1.4.2.2. https://CRAN.Rproject.org/package $=\mathrm{gdm}$

Gamba, D., Muchhala, N. 2020. Global patterns of population genetic differentiation in seed plants. M,,ol Ecol, 29, 3413-3428.

García-Rodríguez, A., Guarnizo, C., Crawford, A.J., Garda, A.A., Costa, G.C. 2020. Idiosyncratic responses to drivers of genetic differentiation in the complex landscapes of Isthmian Central America. Heredity,https://doi.org/10.1038/s41437-020-00376-8.

Gelmi-Candusso, T.A., Heymann, E.W., Heer, K. 2017. Effects of zoochory on the spatial genetic structure of plant populations. Mol. Ecol ., 26, 5896-5910.

Gentry, A.H. 1982. Neotropical floral diversity: phytogeographical connections between Central and South America, Pleistocene climatic fluctuations or an accident of the Andean orogeny? Ann. Miss. Bot. Gard, 69, 557-593.

Gowda, V., Kress, W.J. 2013. A geographic mosaic of plant-pollinator interactions in the eastern Caribbean islands. Biotropica, 45, 224-235. 
Gutiérrez-Rodríguez, C., Ornelas, J.F., Rodríguez-Gómez, F. 2011. Chloroplast DNA phylogeography of a distylous shrub (Palicourea padifolia, Rubiaceae) reveals past fragmentation and demographic expansion in Mexican cloud forests. Mol. Phylogenet. Evol, 61, 603-615.

Hadley, A.S., Betts, M.G. 2012. The effects of landscape fragmentation on pollination dynamics: absence of evidence not evidence of absence.Biol. Rev, 87, 526-544.

Haffer, J. 1969. Speciation in Amazonian forest birds. Science 165: 131-137.

Hanks EM. 2018. rwc: Random Walk Covariance Models. R package version 1.11. https://CRAN.Rproject.org/package $=$ rwc.

Hanson, L., McMahon, K.A., Johnson, M.A.T., Bennett, M.D. 2001. First nuclear DNA C-values for 25 angiosperm families. Ann. Bot, 87, 251-258.

Helmstetter, A.J., Béthune, K., Kamdem, N.G., Sonké, B., Couvreur, TLP. 2020. Individualistic evolutionary responses of Central African rain forest plants to Pleistocene climatic fluctuations. PNAS, 117, 3209-32518.

Hernández-Langford, D.G., Siqueiros-Delgado, M.E., Ruíz-Sánchez. 2020. Nuclear phylogeography of the temperate tree speciesChiranthodendron pentadactylon (Malvaceae): Quarternary relicts in Mesoamerican cloud forests. BMC Evol Biol, 20, 44.

Hijmans, R.J., S.E. Cameron, J.L. Parra, P.G. Jones and A. Jarvis, 2005. Very high resolution interpolated climate surfaces for global land areas. International Journal of Climatology 25: 1965-1978.

Hijmans, R.J. 2017. geosphere: Spherical Trigonometry. R package version 1.5-7. https://CRAN.Rproject.org $/$ package $=$ geosphere.

Hughes, M., Möller, M., Edwards, T.J., Bellstedt, D.U., DeVilliers, M. 2007. The impact of pollination syndrome and habitat on gene flow: a comparative study of two Streptocarpus (Gesneriaceae) species.Am. J. Bot, 94, 1688-1695.

Jørgensen, P. M., Ulloa-Ulloa, C. 1994. Seed plants of the High Andes of Ecuador: A checklist. AAU Rep, $34,1-443$.

Karger, D.N., Conrad, O., Böhner, J., Kawohl, T., Kreft, H., Soria-Auza, R.W., et al . 2017. Climatologies at high resolution for the earth's land surface areas. Scientific Data , 4, 170122.

Karger, D. N., Nobis, M. P., Normand, S., Graham, C. H., \& Zimmermann, N. E. 2021. CHELSA-TraCE21k v1. 0. Downscaled transient temperature and precipitation data since the last glacial maximum. Climate of the Past Discussions, 1-27.

Kartzinel, T.R., Shefferson, R.P., Trapnell, D.W. 2013. Relative importance of pollen and seed dispersal across a Neotropical mountain landscape for an epiphytic orchid. Mol. Ecol, 22, 6048-6059.

Kisel, Y., Barraclough, T.G. 2010. Speciation has a spatial scale that depends on levels of gene flow. Am Nat, 175, 316-334.

Korneliussen, T.S., Albrechtsen, A., Nielsen, R. 2014. ANGSD: Analysis of Next Generation Sequencing Data. BMC Bioinformatics, 15, 356.

Kramer, A.T., Fant, J.B., Ashley, M.V. 2011. Influence of landscape and pollinators on population genetic structure: Examples from threePenstemon (Plantaginaceae) species in the Great Basin. Am J Bot, 98, 109121.

Krauss, S.L., He, T., Barrett, L.G., Lamont, B.B., Enright, N.J., Miller, B.P., et al . 2008. Contrasting impacts of pollen and seed dispersal on spatial genetic structure in the bird-pollinatedBanksia hookeriana . Heredity, 102, 274-285. 
Krauss, S.L., Phillips, R.D., Karron, J.D., Johnson, S.D., Roberts, D.G., Hopper, S.D. 2017. Novel consequences of bird pollination for plant mating. Trends in Plant Sci, 22, 395- 410.

Lagomarsino LP, Condamine FL, Antonelli A, Mulch A, Davis CC. 2016. The abiotic and biotic drivers of rapid diversification in Andean bellflowers (Campanulaceae). New Phytol . 210: 1430-1442.

Li, H., Durbin, R. 2009. Fast and accurate short read alignment with Burrows-Wheeler transform. Bioinformatics, 25, 1754-1760.

Luebert, F., Weigend, M. 2014. Phylogenetic insights into Andean plant diversification. Front. Ecol. Evol, $2,10.3389 /$ fevo.2014.00027.

Maas, D.L., Prost, S., Bi, K., Smith, L.L., Armstrong, E.E., Aji, L.P., et al . 2018. Rapid divergence of mussel populations despite incomplete barriers to dispersal. Mol, Ecol , 27, 1556-1571.

McKenna, A., Hanna, M., Banks, E., Sivachenko, A., Cibulskis, K., Kernytsky, A., et al . 2010. The Genoma Analysis Toolkit: a MapReduce framework for analyzing next-generation DNA sequencing data.Genome Res , 20, 1297-1303.

Meisner, J., Albrechtsen, A. 2018. Inferring population structure and admixture proportions in low-depth NGS data. Genetics, 210, 719-731.

Moncada, B., Mercado-Díaz, J.A., Magain, N., Hodkinson, B.P., Smith, C.W., Bungartz, F., et al. 2021. Phylogenetic diversity of two geographically overlapping lichens: isolation by distance, environment, or fragmentation? J Biogeo, 48, 676-689.

Nazareno, A.G., Knowles, L.L., Dick, C.W., Lohmann, L.G. 2021. By animal, water or wind: can dispersal mode predict genetic connectivity in riverine plant species? Front Plant Sci, 12, 626405.

Nevado, B., Contreras-Ortiz, N., Hughes, C., Filatov, D.A. 2018. Pleistocene glacial cycles drive isolation, gene flow and speciation in the high-elevation Andes. New Phytol, 219, 779-793.

Oksanen, J., Blanchet, F.G., Friendly, M., Kindt, R., Legendre, P., McGlinn, D., et al . 2019. vegan: Community Ecology Package. R package version 2.5-5. https://CRAN.R-project.org/package=vegan

Opedal, Ø.H., Falahati-Anbaran, M., Albertsen, E., Armbrustser, W.S., Pérez-Barrales, R., Stenøien, H.K., et al . 2016. Euglossine bees mediate only limited long-distance gene flow in a tropical vine. New Phytol, 213, 1898-1908.

Ornelas, J.F., Ruiz-Sánchez, E., Sosa, V. 2010. Phylogeography ofPodocarpus matudae (Podocarpaceae): pre-Quaternary relicts in northern Mesoamerican cloud forests. J Biogeo, 37, 2384-2396.

Ornelas, J.F., Sosa, V., Soltis, D.E., Daza, J.M., González, C., Soltis, P.S., et al . 2013. Comparative phylogeographic analyses illustrate the complex evolutionary history of threatened cloud forests of northern Mesoamerica. PLoS ONE, 8, e56283.

Ornelas, J.F., Ortiz-Rodríguez, A.E., Ruiz-Sanchez, E., Sosa, V., Pérez-Farrera, M.Á. 2019. Ups and downs: Genetic differentiation among populations of the Podocarpus (Podocarpaceae) species in Mesoamerica. Mol Phyl Evol, 138, 17-30.

Ortego, J., Gugger, P.E., Sork, V.L. 2014. Climatically stable landscapes predict patterns of genetic structure and admixture in the Californian canyon live oak. J Biogeo, 42, 328-338.

Otto, F., Oldiges, H., Goehde, W., Jain, V.K. 1981. Flow cytometric measurement of nuclear DNA content variations as a potential in vivo mutagenicity test. Cytometry, 2, 189-191.

Paris, J.R., Stevens, J.R., Catchen, J.M. 2017. Lost in parameter space: a road map for STACKS. Meth Ecol Evol, 8, 1360-1373. 
Patten, M.A., Smith-Patten, B.D. 2008. Biogeographical boundaries and Monmonier's algorithm: a case study in the northern neotropics. J Biogeo, 35, 407-416.

Paun, O., Turner, B., Trucchi, E., Munzinger, J., Chase, M.W., Samuel, R. 2016. Processes driving the adaptive radiation of a tropical tree (Diospyros, Ebenaceae) in New Caledonia, a biodiversity hotspot.Syst Biol, 65, 212-227.

Pröhl, H., Ron, S.R., Ryan, M.J. 2010. Ecological and genetic divergence between two lineages of Middle American túngara frogs Physalaemus(=Engystomops ) pustulosus . BMC Evol Biol, 10,146.

R Core Team. 2020. R: A language and environment for statistical computing. R Foundation for Statistical Computing, Vienna, Austria. http://www.r-project.org/index.html.

Rahbek, C., Borregaard, M.K., Antonelli, A., Colwell, R.K., Holt, B.G., Nogues-Bravo, D., et al. 2019. Building mountain biodiversity: Geological and evolutionary processes. Science, 365, 1114-1119.

Ramírez-Barahona, S., Eguiarte, L.E. 2013. The role of glacial cycles in promoting genetic diversity in the Neotropics: the case of cloud forests during the Last Glacial Maximum. Ecol Evol, 10.1002/ece3.483.

Rangel, T.F., Edwards, N.R., Holden, P.B., Diniz-Filho, J.A.F., Gosling, W.D., Coelho, M.T.P., et al. 2018. Modelling the ecology and evolution of biodiversity: Biogeographical cradles, museums, and graves.Science, 361 , eaar5452.

Schmidt-Lebuhn, A.N., Müller, M., Pozo, I.P., Encinas, V.F., Kessler, M. 2019. Pollen analogues are transported across greater distances in bee-pollinated than in hummingbird-pollinated species of Justicia(Acanthaceae). Biotropica, 51, 99-103.

Schoen, D.J., Clegg, M.T. 1984. Estimation of mating system parameters when outcrossing events are correlated. PNAS, 81, 5258-5262.

Serrano-Serrano ML, Rolland J, Clark JL, Salamin N, Perret M. 2017. Hummingbird pollination and the diversification of angiosperms: an old and successful association in Gesneriaceae. Proc. R. Soc. Lond. B284: 20162816.

Skogen, K.A., Overson, R.P., Hilpman, E.T., Fant, J.B. 2019. Hawkmoth pollination facilitates long-distance pollen dispersal and reduces isolation across a gradient of land-use change. Ann Miss Bot Gard, 104, 495-511.

Skotte, L., Korneliussen, T. S., \& Albrechtsen, A. 2013. Estimating individual admixture proportions from next generation sequencing data.Genetics , 195, 693-702.

Surget-Groba, Y., Kay, K.M. 2013. Restricted gene flow within and between rapidly diverging Neotropical plant species. Mol Ecol,22, 4931-4942.

Swets, J.A. 1988. Measuring the accuracy of diagnostic systems.Science, 240, 1285-1293.

Temsch, E.M., Greilhuber, J., Krisai, R. 2010. Genome size in liverworts. Preslia, 82, 63-80.

Toon, A., Cook, L.G., Crisp, M. 2014. Evolutionary consequences of shifts to bird-pollination in the Australian pea-flowered legumes (Mirbelieae and Bossiaeeae). BMC Evol Biol, 14, 43.

Trénel, P., Hansen, M.M., Normand, S., Borchenius, F. 2008. Landscape genetics, historical isolation and cross-Andean gene flow in the wax palm, Ceroxylon echinulatum (Arecaceae). Mol Ecol, 17, 3528-3540.

Valavi R, Elith J, Lahoz-Monfort JJ, Guillera-Arroita G. blockCV: An R package for

generating spatially or environmentally separated folds for k-fold cross-validation of species distribution models. Methods Ecol Evol. 2019; 10:225-232.

Valencia, B.G., Urrego, D.H., Silman, M.R., Bush, M.B. 2010. From ice age to modern: a record of landscape change in an Andean cloud forest.J Biogeo, 37, 1637-1647. 
Van der Niet, T., Peakall, R., Johnson, S.D. 2014. Pollinator-driven ecological speciation in plants: new evidence and future perspectives.Ann Bot , 113, 199-212.

Van Etten, J. 2017. R package gdistance: Distances and routes on geographical grids. J Stat Soft, 76, 1-21.

Vasconcellos, M.M., Colli, G.R., Weber, J.N., Ortiz, E.M., Rodrigues, M.T., Cannatella, D.C. 2019 . Isolation by instability: Historical climate change shapes population structure and genomic divergence of treefrogs in the Neotropical Cerrado savanna. Mol Ecol, 28, 1748-1764.

Vieira, F.G., Fumagalli, M., Albrechtsen, A. 2013. Estimating inbreeding coefficients from NGS data: Impact on genotype calling and allele frequency estimation. Genome Research, 23, 1852-1861.

Vieira, F.G., Lassalle, F., Korneliussen, T.S., Fumagalli, M. 2016. Improving the estimation of genetic distances from Next-Generation Sequencing data. Biol J Linn Soc, 117, 139-149.

Vignali, S, Barras, AG, Arlettaz, R, Braunisch, V. 2020. SDMtune: An R package to tune and

evaluate species distribution models. Ecol Evol: 00: 1- 18.

Wang, I.J. 2013. Examining the full effects of landscape heterogeneity on spatial genetic variation: a multiple matrix regression approach for quantifying geographic and ecological isolation. Evolution, 67, 3403-3411.

Warmuth, V.M., Ellegren, H. 2019. Genotype-free estimation of allele frequencies reduces bias and improves demographic inference from RADseq data. Mol Ecol Res, 19, 586-596.

Warnes, G.R., Bolker, B., Bonebakker, L., Gentleman, R., Huber, W., Liaw, A., et al. 2020. gplots: Various $\mathrm{R}$ programming tools for plotting data. $\mathrm{R}$ package version 3 .

Weigend, M. 2002. Observations on the biogeography of the Amotape-Huancabamba zone in northern Peru. Bot Rev , 68, 38-54.

Wessinger, C. 2021. From pollen dispersal to plant diversification: genetic consequences of pollination mode. New Phytol , 229, 3125-3132.

Whelan, R.J., Ayre, D.J., Beynon, F.M. 2009. The birds and the bees: pollinator behaviour and variation in the mating system of the rare shrub Grevillea macleayana. Ann Bot, 103, 1395-1401.

Wysoker, A., Tibbetts, K., Fennell, T. 2013. Picard Tools Version 1.90. Available at: http://picard.sourceforge.net.

Yu, H., Nason, J.D., Ge, X., Zeng, J. 2010. Slatkin's paradox: when direct observation and realized gene flow disagree. A case study inFicus . Mol Ecol, 19, 4441-4453.

Zizka, A., Silvestro, D., Andermann, T., Azevedo, J., Duarte Ritter, C., Edler, D., et al . 2019. CoordinateCleaner: standardized cleaning of occurrence records from biological collection databases. Meth Ecol Evol, 10,7 .

\section{Data accessibility and benefit sharing}

All new genomic sequence data is currently being uploaded to NCBI Short Reads Archive (BioProject ID PRJ9027591). Input data for niche modelling and exemplary R-scripts for $A$. costaricensis have been deposited on the public repository Phaidra (https://phaidra.univie.ac.at/o:1368440).

\section{Author contributions}

ASD, JS and OP conceived and designed the study, ASD and DFF performed fieldwork, ASD, JB and EMT conducted lab work, ASD and OP analysed the genomic data, ASD performed niche modelling and wrote the first draft, all authors contributed to revising the manuscript. 

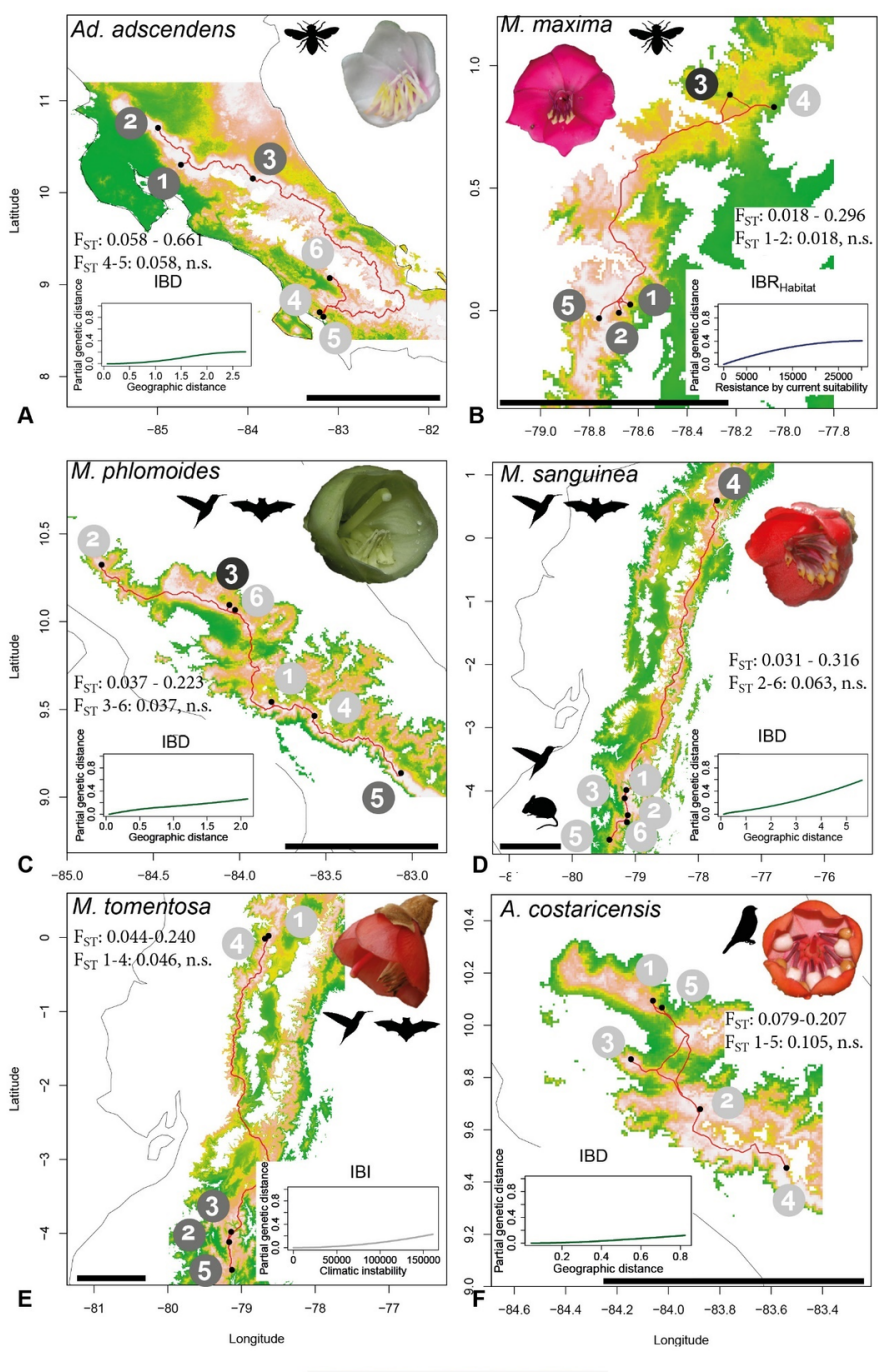

$\begin{array}{llllll}0 & .2 & .4 & .6 & .8 & 1\end{array}$

Figure 1. Sampled localities (red dots, grey circles give population ID and clustering as estimated from admixture analyses (Fig. 3)) depicted on maps of habitat suitability $\left(\mathrm{IBR}_{\mathrm{Habitat}}, 0\right.$ - unsuitable, 1 - highly suitable). Red lines represent least-cost distances between study localities, white areas on maps represent elevations below/above possibly suitable distribution ranges (for habitat suitability across full distribution, see Fig. S3). Per-species $\min / \max \mathrm{F}_{\mathrm{ST}}$ is given, as well as the pairwise $\mathrm{F}_{\mathrm{ST}}$ for the two adjacent populations. I-spline plots show the variable most strongly explaining population genetic differentiation as estimated through GDM (Table 2). Black bars represent $100 \mathrm{~km}$, black outlines represent coast lines of Costa Rica and Ecuador. A: Bee-pollinated Ad. adscendens, lowland rainforests, Costa Rica; B: Bee-pollinated M. maxima, montane cloud forests, Ecuador; C: Hummingbird-bat-pollinated M. phlomoides, montane cloud forests, Costa Rica; D: M. sanguinea with hummingbird-rodent-pollinated southern populations and hummingbird-bat-pollinated northern population, cloud forest-Páramo ecotone, Ecuador; 
note that while rodents (ground-dwelling mammals) are considered as relativly immobile pollinators, we found high connectedness among localities, possibly attributable to traplining hummingbird pollinators; E: hummingbird-bat-pollinated M. tomentosa, cloud forests, Ecuador; F: passerine-pollinated A. costaricensis, cloud forests, Costa Rica.
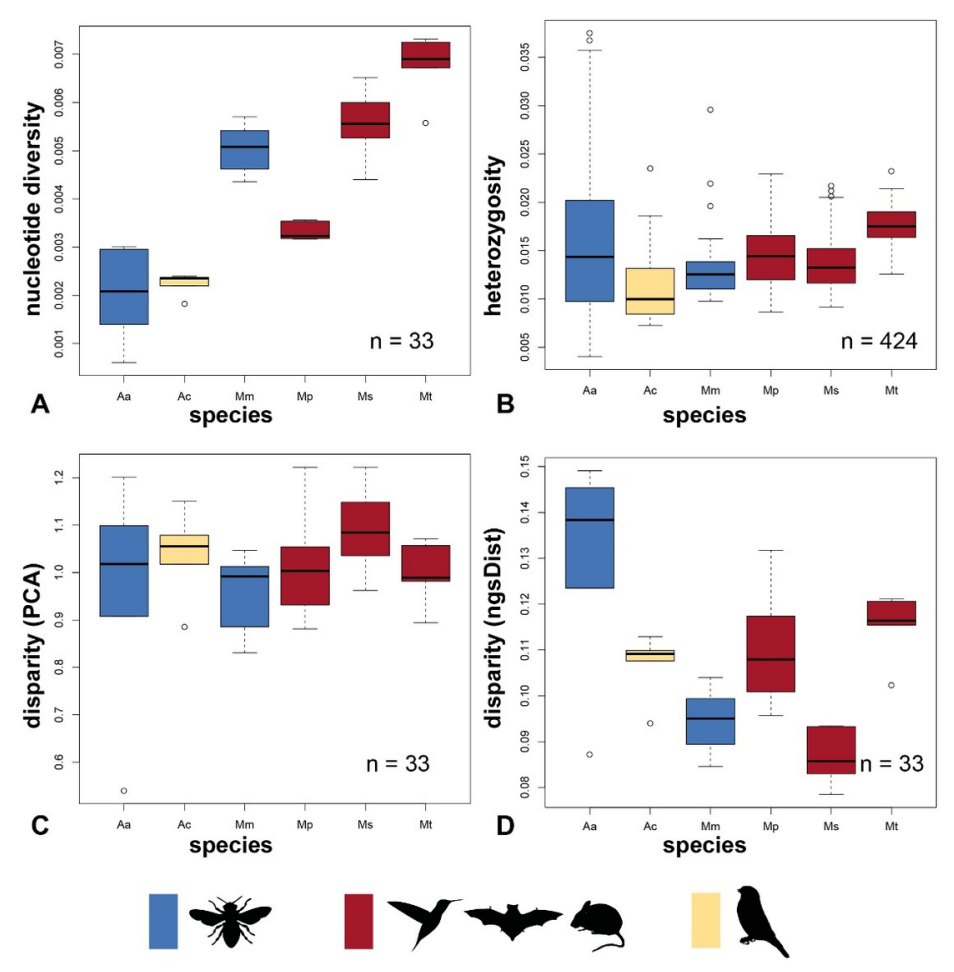

Figure 2. Population genetic summary statistics (per site nucleotide diversity, heterozygosity and disparity) for the six study species, colour coded according to pollination strategy. A) Population nucleotide diversity differed significantly among species, but not among pollination strategies. B) Individual heterozygosity differed significantly among species, but not among pollination strategies. C) Disparity (variance in genetic diversity estimated on covariance matrix) did not differ significantly among pollination strategies. D) Disparity (variance in genetic diversity estimated through ngsDist) did not differ significantly 
among pollination strategies. Colours indicate the different pollination strategies. Aa-Adelobotrys adscendens, Ac-Axinaea costaricensis, $M m-M$. maxima, $M p-M$. phlomoides, Ms - M. sanguinea, Mt $-M$. tomentosa .
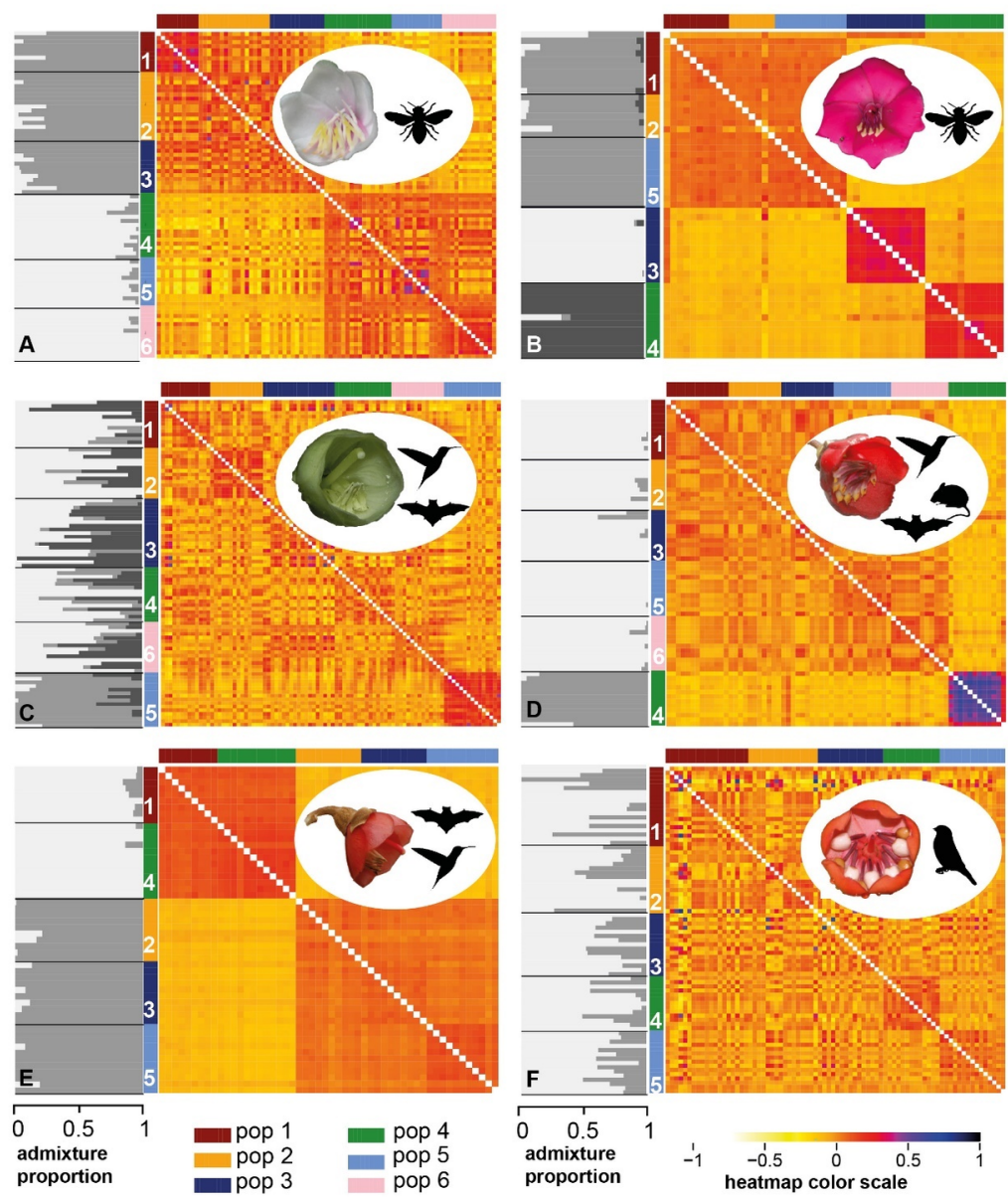

Figure 3. Population structure and co-ancestry of the six study species. The grey-scale bar plots (left) give admixture proportions according to the K-value best describing clustering in the data. In co-ancestry heatmaps (right), darker tones represent higher pairwise relatedness and stronger differentiation from other individuals. Note that $\mathrm{D}$ and $\mathrm{E}$ were sampled across much larger distances than the other species. (A) Localities of bee-pollinatedAdelobotrys adscendens form two clusters with low admixture proportions (best $\mathrm{K}=2$ ), localities 1, 2 and 3 in Northern and Central Costa Rica and localities 4,5 and 6 in Southern Costa Rica; locality 1 being significantly less disparate than the others (Table S17, S18); heatmaps indicate 
relatively high relatedness within clusters, and considerable relatedness among individuals between clusters. (B) Bee-pollinated Meriania maxima with three clusters and very little admixture among clusters: one cluster comprising three intermixed, undifferentiated localities (1,2 and 5 from North-Central Ecuador, Table S15, S16), and distinct localities 3 and 4 (only $20 \mathrm{~km}$ apart) differing significantly from each other and all other localities, with high shared co-ancestry within these localities. (C) We detected three ancestral clusters in hummingbird-bat-pollinated M. phlomoides, with overall weak clustering, high admixture and high shared co-ancestry across localities; localities 1, 2, 3, 4 and 6 were intermixed and only locality 5 differed significantly from 1, 2, 4 and 6; locality 3 was significantly more variable than the others (Table S17). (D) In hummingbird-bat-rodent-pollinated M. sanguinea, the five hummingbird-rodent-pollinated localities from Southern Ecuador clustered together with low admixture and shared co-ancestry across localities. They were significantly different from locality 4 (Northern Ecuador, hummingbird-bat-pollinated, Table S15) and also showed floral adaptations to their different nocturnal (rodent/bat) pollinators (Table S1, Dellinger et al. 2019b). (E) We detected two ancestral clusters with low admixture in hummingbird-batpollinated $M$. tomentosa, localities 1 and 4 (Norther Ecuador) differed significantly from localities 2, 3 and 5 (Southern Ecuador, Table S15, S16), with low shared co-ancestry between those clusters. (F) All localities were intermixed without clear clustering (best $\mathrm{K}=2$ ) in passerine-pollinatedAxinaea costaricensis , with considerable admixture and shared co-ancestry among all localities.

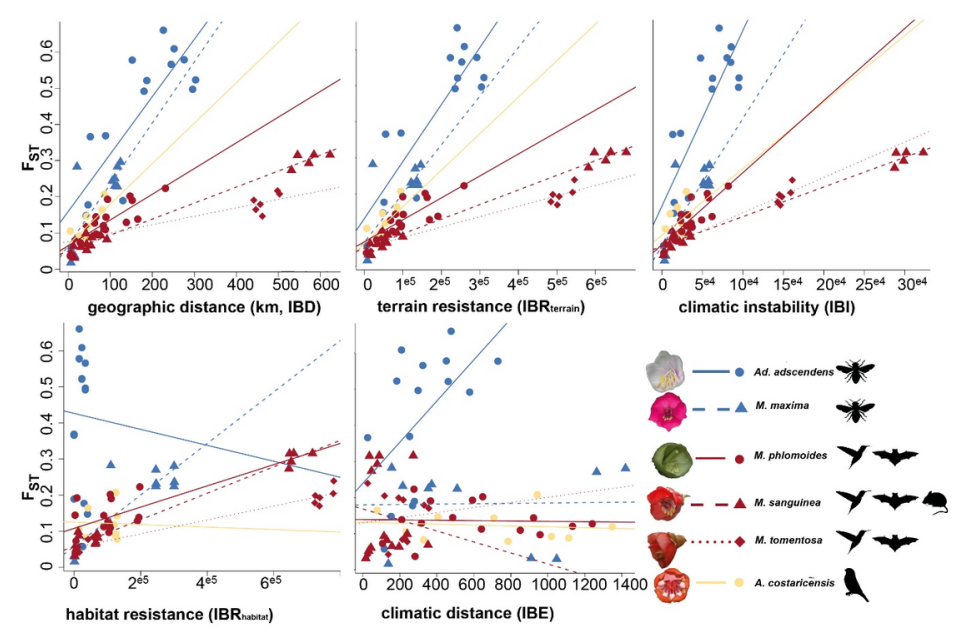

Figure 4. Relation between genetic distance $\left(\mathrm{F}_{\mathrm{ST}}\right)$ and geographic distance (IBD), topographic barriers $\left(\right.$ IBR $\left._{\text {Terrain }}\right)$, climatic instability (IBI), habitat suitability (IBR Habitat $_{\text {) }}$ ) and climatic distance (IBE) in the six study species. We detected significant IBD/IBR/IBI in all species but A. costaricensis, and no IBE in any species. Our results suggest that large geographic distances among localities of species pollinated by less mobile bee pollinators (blue) result in larger genetic differentiation than in species pollinated by mixed assemblages of (volant) vertebrates (red, yellow). Correlations of genetic distance and current habitat suitability and climatic variables were (mostly) not significant. Relations are depicted for each species separately; each dot represents a pairwise population comparison.

Table 1. Results of Mantel's tests on the impact of IBD, IBR $\mathbf{I T r r a i n}_{\text {, }} \mathbf{I B R}_{\mathrm{Habitat}}$, IBI and IBE on normalized population genetic differentiation $\left(\mathbf{F}_{\mathbf{S T}}\right)$. Significant isolation by distance and/or resistance in all species but $A$. costaricensis, no IBE, the highest significant $\mathrm{R}^{2}$ for each species is highlighted in bolt, significant values in italics. 


\begin{tabular}{llllllllll}
\hline species & IBD & IBD & IBRTerrain & IBRTerrain & IBRHabitat & IBRHabitat & IBI & IBI & IBE \\
\hline & $\mathbf{R}^{\mathbf{2}}$ & $\mathrm{p}$ & $\mathbf{R}^{\mathbf{2}}$ & $\mathrm{p}$ & $\mathbf{R}^{\mathbf{2}}$ & $\mathrm{p}$ & $\mathbf{R}^{\mathbf{2}}$ & $\mathrm{p}$ & $\mathbf{R}^{\mathbf{2}}$ \\
Ad. adscendens & 0.785 & 0.047 & 0.821 & 0.053 & 0.017 & 0.470 & 0.796 & 0.048 & 0.556 \\
M. maxima & 0.687 & 0.017 & 0.673 & 0.017 & 0.777 & 0.023 & 0.729 & 0.016 & 0.091 \\
M. phlomoides & 0.815 & 0.006 & 0.784 & 0.008 & 0.363 & 0.171 & 0.808 & 0.002 & -0.108 \\
M. sanguinea & 0.987 & 0.005 & 0.987 & 0.007 & 0.984 & 0.01 & 0.985 & 0.011 & -0.150 \\
M. tomentosa & $\mathbf{0 . 9 5 1}$ & $\mathbf{0 . 0 1 5}$ & 0.948 & 0.016 & 0.941 & 0.024 & 0.950 & 0.017 & -0.016 \\
A. costaricensis & $\mathbf{0 . 7 5 0}$ & $\mathbf{0 . 0 5 5}$ & 0.675 & 0.074 & -0.002 & 0.547 & 0.417 & 0.073 & -0.093 \\
\hline
\end{tabular}

Table 2. Importance (Imp.) of IBD, IBR Terrain, $\mathrm{IBR}_{\text {Habitat }}$, IBI and IBE on explaining population genetic differentiation $\left(\mathbf{F}_{\mathbf{S T}}\right)$ as assessed through GDM (compare Table S20, Figs. S4-S10); Imp.-1/-2/-3 give models where, sequentially, the respective explanatory variable(s) contributing least to model fit were removed (indicated by empty space). Note that models may fail to fit if relationships between $\mathrm{F}_{\mathrm{ST}}$ and (some) explanatory variables are weak (indicated by "/").

\begin{tabular}{|c|c|c|c|c|c|c|c|c|}
\hline Ad. adscendens & Imp. & p-value & Imp.-1 & p-value & Imp.-2 & p-value & Imp.-3 & p-value \\
\hline IBD & 0.208 & 0.016 & 0.208 & 0.005 & 0.723 & 0.014 & 64.328 & 0.014 \\
\hline IBRTerrain & 0.237 & 0.146 & 0.237 & 0.150 & 0.238 & 0.162 & & \\
\hline IBRHabitat & 0 & 0.814 & & & & & & \\
\hline IBI & 0.000 & 0.346 & 0.000 & 0.324 & & & & \\
\hline $\begin{array}{l}\text { IBE } \\
\text { M. maxima }\end{array}$ & 0.817 & 0.172 & 0.817 & 0.156 & 0.817 & 0.158 & 2.710 & 0.184 \\
\hline $\begin{array}{l}\text { IBD } \\
\text { IBRTerrain }\end{array}$ & $\begin{array}{l}0.022 \\
0\end{array}$ & $\begin{array}{l}<0.001 \\
1\end{array}$ & 0.022 & $<0.001$ & 0.022 & $<0.001$ & 0.274 & $<0.001$ \\
\hline IBRHabitat & 10.869 & 0.226 & 10.869 & 0.230 & 30.853 & $<0.001$ & 30.637 & $<0.001$ \\
\hline $\begin{array}{l}\text { IBI } \\
\text { IBE }\end{array}$ & $\begin{array}{l}0 \\
0.311\end{array}$ & $\begin{array}{l}1 \\
0.614\end{array}$ & $\begin{array}{l}0 \\
0.311\end{array}$ & $\begin{array}{l}1 \\
0.628\end{array}$ & 0.311 & 0.600 & & \\
\hline M. phlomoides & & & & & & & & \\
\hline IBD & 2.393 & 0.008 & 2. 7777 & 0.008 & 2.777 & 0.005 & 99.919 & 0.016 \\
\hline $\begin{array}{l}\text { IBRTerrain } \\
\text { IBRHabitat }\end{array}$ & $\begin{array}{l}0 \\
0\end{array}$ & $\begin{array}{l}1 \\
1\end{array}$ & & & & & & \\
\hline $\begin{array}{l}\text { IBRHabitat } \\
\text { IBI }\end{array}$ & 0.005 & $\begin{array}{l}1 \\
0.512\end{array}$ & $\begin{array}{l}0 \\
0.005\end{array}$ & $\begin{array}{l}1 \\
0.496\end{array}$ & 0.005 & 0.506 & & \\
\hline $\begin{array}{l}\text { IBE } \\
\text { M. sanguinea }\end{array}$ & 0.398 & 0.370 & 0.398 & 0.316 & 0.398 & 0.215 & / & / \\
\hline $\begin{array}{l}\text { IBD } \\
\text { IBRTerrain }\end{array}$ & $\begin{array}{l}0.035 \\
0\end{array}$ & $\begin{array}{l}0.021 \\
0.830\end{array}$ & $\begin{array}{l}0.035 \\
0\end{array}$ & $\begin{array}{l}0.016 \\
0.836\end{array}$ & 0.687 & 0.016 & / & / \\
\hline $\begin{array}{l}\text { IBRTerrain } \\
\text { IBRHabitat }\end{array}$ & $\begin{array}{l}0 \\
0.000\end{array}$ & $\begin{array}{l}0.830 \\
0.514\end{array}$ & $\begin{array}{l}0 \\
0.000\end{array}$ & $\begin{array}{l}0.836 \\
0.496\end{array}$ & 0.000 & 0.490 & & \\
\hline IBI & 0.000 & 0.832 & & & & & & \\
\hline $\begin{array}{l}\text { IBE } \\
\text { M. tomentosa }\end{array}$ & 0.861 & 0.134 & 0.861 & 0.168 & 0.879 & 0.200 & 0.879 & 0.146 \\
\hline $\begin{array}{l}\text { IBD } \\
\text { IBRTerrain }\end{array}$ & $\begin{array}{l}2.193 \\
0\end{array}$ & $\begin{array}{l}<0.001 \\
1\end{array}$ & 2.193 & $<0.001$ & 2.193 & $<0.001$ & 2.193 & $<0.001$ \\
\hline IBRHabitat & 0 & 1 & 0.000 & 1 & 0.000 & 1 & & \\
\hline IBI & 0.225 & 0.410 & 1.157 & 0.206 & 1.157 & 0.170 & 55.832 & $<0.001$ \\
\hline $\begin{array}{l}\text { IBE } \\
\text { A. costaricensis }\end{array}$ & 0 & 1 & 0 & 1 & & & & \\
\hline IBD & 14.532 & 0.309 & 68.258 & 0.310 & 68.258 & 0.334 & / & / \\
\hline
\end{tabular}




\begin{tabular}{lllllllll}
\hline Ad. adscendens & Imp. & p-value & Imp.-1 & p-value & Imp.-2 & p-value & Imp.-3 & p-value \\
\hline IBRHabitat & 0 & 1 & 0 & 1 & & & & \\
IBI & 0 & 1 & 0 & 1 & 0 & 1 & & \\
IBE & 0 & 1 & 0 & 1 & 0 & 1 & 0 & 1 \\
\hline
\end{tabular}

